\title{
La complejidad de lo complejo
}

The complexity of the complex

\author{
Eugenio Rivas Herencia \\ Departamento de Arte y Arquitectura, Universidad de Málaga, España (eugeniorivas@uma.es)
}

Recibido el 15 de junio de 2017; revisado el 20 de junio de 2017; aceptado el 30 de julio de 2017; publicado el 01 de septiembre de 2017

RESUMEN: La presente investigación analiza el pensamiento complejo de Edgar Morin para refutar la hipótesis que defiende la imposibilidad de aprehender lo real desde una visión racionalista especializada. En su lugar se defiende el poder de un conocimiento múltiple que acepte la indecibilidad de nuestro mundo, la imposibilidad de ceñirlo bajo los parámetros de la razón para convertirlo en ideas. El objetivo del estudio es aceptar la verdad como convención.

PALABRAS CLAVE: Arte, pensamiento, complejidad, indecibilidad, realidad, verdad.

\begin{abstract}
This research analyzes the complex thought of Edgar Morín to refute the hypothesis that defends the impossibility of apprehending reality from a specialized rationalist view. In its place is defended the power of a multiple knowledge that accepts the unspeakability of our world, the impossibility of sticking it under the parameters of reason to turn it into ideas. The aim of the study is to accept truth as a convention.
\end{abstract}

KEYWORDS: Art, thinking, complexity, unspeakability, reality, truth. 
La misma idea de complejidad lleva en sí la imposibilidad de unificar, la imposibilidad del logro, una parte de incertidumbre, una parte de indecibilidad, y el reconocimiento del encuentro cara a cara, final, con lo indecible.

Edgar Morin.

Si nos referimos a ámbitos como la Biofísica, los estudios antropo-sociales o psico-mitológicos comprobamos las distintas perspectivas desde las que la humanidad puede acercarse al mundo a través del ejercicio del pensamiento. Edgar Morin establece puentes entre los diferentes campos, abordándolos transversalmente, para plantear una comprensión o entendimiento complejo. En todo su trabajo reina una preocupación de carácter ética que es incluida como elemento central en la observación de los procesos sociales. Esta aventura o desafío intelectual de la complejidad que Morin propone, consiste en pensar complejamente como metodología de acción cotidiana, sea cual sea el campo en el que desempeñemos nuestro quehacer, aclara Marcelo Packman en la introducción al trabajo de Morin: "Es complejo aquello que no puede resumirse en una palabra maestra, aquello que no puede retrotraerse a una ley, aquello que no puede reducirse a una idea simple. [...] La complejidad es una palabra problema y no una palabra solución" (Morin, 1997, p. 21). Lejos de controlar y dominar, el pensamiento complejo propone la ejercitación para tratar, dialogar, negociar con lo real. Sabe que el conocimiento completo, absoluto, es imposible, igual que sabe que todo está relacionado.

Esto ocurre de tal manera que el pensamiento complejo está animado por una tensión permanente entre la aspiración de un saber no parcelado, no dividido, no reduccionista, y el reconocimiento de lo inacabado e incompleto de todo conocimiento. La complejidad no es la clave del mundo, sino, más bien, un desafío a afrontar su realidad múltiple. Así mismo, el pensamiento complejo no evita o suprime dicho desafío, no lo resuelve, sino que, mejor aún, ayuda a su revelación proponiendo niveles superiores para el reto de la comprensión. Con el ánimo de ordenar, de entender, se ha mutilado la pluralidad de lo real para reducirla a lo inteligible. Un ánimo que lo mismo que nos ha ayudado a ver, nos ha vuelto ciegos: "Un pensamiento mutilante $\downarrow$ afirma Morin $\downarrow$ condxe, necesariamente, a acciones mutilantes." (Morin, 1997, p. 32). El que no piense con complejidad tampoco podrá actuar complejamente. 
Este planteamiento general recuerda al concepto de rizoma desarrollado por Gilles Deleuze y Félix Guattari (Deleuze y Guattari, 1973)1. El pensamiento complejo tiene un noble aliado en el pensamiento nómada que Deleuze defendía dentro de la herencia posmoderna de Nietzsche. Diferentes perspectivas que se ponen de acuerdo para defender un sistema de pensamiento liberado de la rigidez platónica que tanto pesa en la historia de la humanidad. La verdad abandona su arrogante rigidez para ponerse en movimiento y conectar teoría y metodología. Una idea que se resume perfectamente con las palabras de Chantal Maillard (Maillard, 2009, pp. 9-10):

"Me he situado "contra" el arte y otros conceptos institucionales como quien se apoya "contra" un muro que, al par que nos ampara, nos coarta. Muros, los de la metafísica, la ciencia, la moral, la política, la religión, las formas consensuadas de emocionarnos social y estéticamente, la filosofía o el arte, que hemos levantado para sostenernos, defendernos o protegernos pero que, cuando cobran solidez, nos impiden ver al otro lado, traspasar el ámbito conocido y aprender otras maneras de caminar, de estar y de relacionarnos con las cosas y, lo que es peor, nos hacen olvidar que alguna vez los hemos construido."

Estamos de acuerdo en que la verdad es una construcción propia y no una realidad imperturbable, absoluta. La denuncia común de estas tendencias de pensamiento (ya sean clasificadas como filosóficas, antropológicas, o sencillamente humanistas) puede resumir su patología en el idealismo, ya que la idea se convierte en el velo de lo real. Así el dogmatismo petrifica la teoría. E igual ocurre con la razón, que se convierte en racionalización y se olvida de su perspectiva parcial, de que una parte de lo real es inaprensible racionalmente. Como diría Bachelard, no existe lo simple, sino lo simplificado, lo disminuido (Bachelard, 1957, p. 54-55).

Cierta mezcla de orden y desorden establece la disposición lógica de la complejidad. La entropía (fenómeno de desorganización) y la negantropía (fenómeno de reorganización) se encuentran aquí inseparablemente unidas. El azar tiene obligada presencia en esta estructura de pensamiento; la incertidumbre también se encuentra inserta por defecto en todos los sistemas organizados. La aceptación de esta mezcla entre orden y desorden supone cierta ambigüedad tanto en los fenómenos como en los conceptos, de modo que cualquier teoría, cualquier definición, se establece a partir de un

${ }^{1}$ Sobre las teorías desarrolladas conjuntamente entre ambos filósofos destacamos DELEUZE, Gilles y GUATTARI, Félix. Rizoma (introducción). Valencia, Pre-textos, 2005; Mil mesetas: Capitalismo y esquizofrenia. Valencia, Pretextos, 2000. Así mismo resulta indispensable la revisión de los ensayos principales de Deleuze como son Lógica del sentido. Barcelona, Ediciones Paidos Ibérica, 2005; Diferencia y repetición. Madrid, Amorrortu editores España, 2006; «Pensamiento nómada». Texto extraído de La isla desierta y otros textos, (pp. 321-332), Barcelona, Pre-textos, 2005. 
acuerdo o convención al que las personas (pocas o muchas personas) han llegado para entenderse, pero que nunca será equiparable al grado de verdad. Expresado de un modo poético en términos de espacio: "Las fronteras del mapa no existen en el territorio, sino sobre el territorio, con alambres de púa y aduaneros" (Morin, 1997, p. 62).

La realidad, el mundo, no poseen por sí mismos los límites que nosotros nos empeñamos en establecer. Fronteras que determinan el uso, pero que no son absolutas. El pensamiento nómada de Deleuze, al que nos referíamos unas líneas más arriba, apuesta por un planteamiento similar. Lo mismo sucede con las revisiones éticas de Chantal Maillard (Maillard, 1998), que también encuentran ciertos paralelismos con los estudios de Félix Duque sobre el habitar arquitectónico del ser humano (Duque, 2007). Si nos centramos en el arte, un tanto de lo mismo: los artistas recuerdan sin descanso que no hay una, sino infinitas formas de trazar un mapa de lo real, que la noción de Verdad, sea cual sea la institución de poder que la defienda, no es más que una entre tantas verdades. Tal vez reside ahí la noción del "todo vale", tal vez por ello la contradicción sea posible en el arte, mientras es desterrada de tantos otros ámbitos.

Del mismo modo, Nelson Goodman reconocía que era difícil adherir una etiqueta filosófica a su trabajo, ya que se oponía "tanto al empirismo como al racionalismo, al materialismo y al idealismo como al dualismo, al esencialismo como al existencialismo, al mecanicismo y al vitalismo, al misticismo y al cientificismo, por no mencionar otras ardientes teorías" (Goodman, 1978, p. 14). Con esa misma actitud, Morin pretende la elaboración de una teoría abierta donde Física, Biología o Antropología no sean cosas distintas, separadas, sino extremidades de un mismo organismo plenamente intercomunicadas, una misma cosa. El error ontológico recae en la voluntad de cerrar, de petrificar, los conceptos según procesos científicos. Un sistema complejo de pensamiento, en cambio, pretende "abrir la posibilidad de un conocimiento a la vez más rico y menos cierto" (Morin, 1997, p. 70). Con ello se expandirá nuestra visión abriéndonos la posibilidad de establecer conexiones entre fenómenos que hasta ahora nos parecían distantes e incluso, muchas veces, contradictorios.

\section{La incertidumbre de la indecibilidad}

Hablaremos a continuación de la indecibilidad, aquello que es imposible descifrar en cualquier estructura lógica. Veamos la siguiente cita en la que Morin nos explica cómo el teorema de Gödel, un planteamiento matemático en principio, funciona en cualquier sistema teórico. Este teorema 
"demuestra que, en un sistema formalizado, hay por lo menos una proposición que es indecible: esa indecibilidad abre una brecha en el sistema, que se vuelve, entonces, incierto" (Morin, 1997, p. 72).

En el caso del arte (si es que puede ser considerado un sistema teórico formalizado) sucede que la proposición indecible se encuentra en el corazón de su definición, de su concepto, de su planteamiento. Así, el arte se ve obligado a reconocer (aunque no siempre de buen gusto) la barrera infranqueable que nos separa de un conocimiento más racional. Es un sistema abierto ya que incorpora en su naturaleza el desconocimiento y la incertidumbre, ya sea conscientemente; o de un modo más ingenuo, bajo el nombre de musa, inspiración u otros nombres o pseudónimos que vienen a denominar el azar.

La apuesta por la transversalidad del conocimiento ha de aceptar la convivencia de la entropía y la negantropía. Algo bien arraigado en la cultura oriental, explicado con conceptos como el Yin y el Yan que reconocen lo incierto, lo ambiguo, lo contradictorio2. Si la ciencia clásica había rechazado el accidente, lo eventual, lo aleatorio, lo singular, Morin propone una reincorporación de todos los fenómenos azarosos. Pero esta vez con un cambio de paradigma. Se trata de "cambiar las bases de partida del racionamiento, las relaciones asociativas y repulsivas entre algunos conceptos iniciales, pero de los cuales depende toda la estructura del razonamiento, todos los desarrollos discursivos posibles" (Morin, 1997, p. 84). Se trata, en definitiva, de buscar la complejidad en cualquiera de los aspectos más livianos de la vida cotidiana, allí donde, por lo general, parece no encontrarse lo complejo.

Estamos de acuerdo con Morin en que una tendencia entrópica mueve al universo hacia el desorden máximo, pero que en su transcurso todo se organiza, se complejiza y se desarrolla. A pesar de su eterno enfrentamiento, el orden y el desorden cooperan de algún modo dotando de un equilibrio aparentemente estable al universo. En la complejidad las contradicciones no son evitadas y el carácter incierto de nuestro mundo es aceptado por encima de cualquier ley. Morin nos invita a reconocer los límites de nuestra lógica, de nuestras capacidades y de los sistemas de entendimiento a los que nos sometemos: "Podemos decir que aquello que es complejo recupera, por una parte, al mundo empírico, la incertidumbre, la incapacidad de lograr la certeza, de formular una ley, de concebir un orden

\footnotetext{
${ }^{2}$ Como acercamiento a estas filosofías véase, por ejemplo, Tao Te Ching escrito por el maestro Lao Tse; o el famoso Bhagavad Gita de autor desconocido. Las referencias bibliográficas completas aparecen en la bibliografía.
} 
absoluto. Y recupera, por otra parte, algo relacionado con la lógica, es decir, con la incapacidad de evitar contradicciones.” (Morin, 1997, p. 99).

No existe una manera unidimensional que nos permita comprender la realidad. La pobreza de toda visión unidimensional, especializada, parcial, se hace evidente cuando nuestra conciencia atiende a la multidimensionalidad.

\section{Razón, racionalidad y racionalización}

En el uso que hacemos de la razón es procedente distinguir dos tendencias generales: una, la racionalidad, es el juego, el diálogo permanente entre nuestra razón y el mundo, que da lugar a estructuras lógicas flexibles y en incesante renovación; la otra es la racionalización, la ingenua imposición de una estructura lógica rígida sobre el universo, obligándolo a someterse bajo unas pautas que no se adaptan a su naturaleza. Pero, si se impone, la segunda de estas tendencias puede llegar a bloquear o incluso destruir a la primera.

¿Qué ocurre cuando el mundo y nuestro sistema lógico dejan de coincidir? Entonces nos vemos obligados a admitir que nuestra razón, el modo en que la utilizamos, es insuficiente. Sin embargo, la racionalización es una patología del pensamiento que consiste en pretender encerrar la realidad dentro de un sistema coherente; descartando, olvidando, o poniendo al margen, todo aquello que contradice, o de algún modo, se resiste a ese sistema coherente.

Es difícil marcar la frontera entre dos maneras de usar la razón como la racionalidad y la racionalización. De un modo u otro, tendemos a evitar la contradicción, conscientes o no de ello, siempre que podamos, "vamos a minimizar o rechazar los argumentos contrarios. Vamos a tener una atención selectiva hacia aquello que favorece a nuestra idea..." (Morin, 1997, p. 102). Y aquí recae el peligro de todo ejercicio de pensamiento: su voluntad de acertar, de estar en lo cierto. Así que son frágiles las barreras entre la racionalización, la racionalidad y (aunque suene alarmante) la paranoia. Como consecuencia, debemos prestar atención sin tregua y ser autocríticos con el ejercicio de nuestra propia razón, con el modo de practicar una lógica que siempre corre grandes riesgos al pretender aprehender una realidad que funciona según reglas diferentes. "Todo conocimiento conlleva el riesgo del error y de la ilusión [...] Reconocer el error y la ilusión es tanto más difícil porque el error y la 
ilusión no se reconocen como tales" (Morin, 1999, p. 25). Y en esta trampa caeremos una y otra vez por más que confiemos en el sistema racional al que nos sometemos.

En la lucha por aprehender lo real hemos de advertir dos grandes propensiones a las que tienden los delirios de la humanidad. Por un lado, la incoherencia absoluta, el azar puro, el absurdo sin más; y por otro, la coherencia absoluta, el dogmatismo de un pensamiento ciego de sí mismo. Veamos si es posible liberarse de la una sin caer en las garras de la otra.

\section{La complejidad y la acción: Programa o estrategia}

Lejos de ser una receta para conocer lo inesperado, la complejidad nos mantiene alerta, nos hace prudentes, "ella nos muestra que no debemos encerrarnos en el contemporaneísmo, es decir, en la creencia de que lo que sucede ahora va a continuar indefinidamente" (Morin, 1997, p. 117). Todo lo importante que sucede, ha sucedido o va a suceder en la historia es totalmente imprevisible. Es esto lo que nos enseña el pensamiento complejo: sacudir la pereza del espíritu que nos hace actuar como si nada inesperado fuese a suceder jamás. Es por ello que el pensamiento complejo no se conforma con un programa, sino que sabe de la necesidad de una estrategia; nos recuerda que la realidad es cambiante y que lo nuevo puede surgir. Resulta inevitable reescribir las palabras de Morin para comprender cómo la complejidad muestra el camino para una manera de actuar que no ampute, sino que crezca, que sea incluyente (Morin, 1999, p. 118):

"Yo creo profundamente que cuanto menos mutilante sea un pensamiento, menos mutilará a los humanos. Hay que recordar las ruinas que las visiones simplificantes han producido, no solamente en el mundo intelectual, sino también en la vida. Suficientes sufrimientos aquejaron [y aquejan desgraciadamente hoy en día] a millones de seres como resultado de los efectos del pensamiento parcial y unidimensional."

Hemos analizado las ventajas y desventajas de dos formas opuestas de organizarse: la primera establece un programa, ya que presupone un orden; la segunda plantea una estrategia que admite variaciones, pues asume el desorden. La estrategia integra lo inesperado para modificar o enriquecer su acción, mientras que el programa se detiene o falla si las circunstancias exteriores no son favorables. La ventaja del programa es su gran economía debido a un automatismo que no requiere reflexión. La estrategia, sin embargo, es dúctil, capaz de modificarse durante el proceso para seguir adelante, pero a cambio requiere un consumo elevado de recursos. La estrategia nos requiere estar atentos poniendo 
todas nuestras capacidades encima de la mesa para poder replantear nuestras maniobras sobre la marcha. El programa, sin embargo, funciona o falla.

Podemos contemplar cómo el factor juego es un factor de desorden, pero también de flexibilidad, como dice Morin. "El desorden constituye la respuesta inevitable, necesaria e incluso, a menudo fecunda, al carácter esclerotizado, esquemático, abstracto y simplificador del orden.” (Morin, 1997, p. 130). De tal modo, la estrategia se convierte en un recurso imprescindible cuando un plan no se adapta a las circunstancias. Es por ello que la empresa del conocimiento debe convertirse una apuesta por la estrategia, llevando a cabo una campaña que elude el plan, lo esquiva, lo sortea, aún consciente del gran gasto energético que esto conlleva, pero amigo de la complejidad, asegurando su eficacia a toda costa.

\section{Conclusiones: La epistemología de la complejidad. Malentendidos}

La complejidad no es perfecta, es incompleta, aunque tampoco cae en la relatividad absoluta ni en el escepticismo. En ella el azar es un factor indispensable, que nunca está solo y que no lo explica todo. Siempre es imprescindible que lo aleatorio se encuentre con una potencialidad organizadora: la realidad sólo funcionará con el juego entre ambos, con la progresión de su baile improvisado. La totalidad, en palabras de Adorno res la no verdad. (Morin, 1997, p. 137). Por ello, la paradoja entre síntesis y desorden es la contradicción trágica que el pensamiento debe afrontar sin llegar jamás a terminar con ella, sin resolverla. Nos encontramos, por tanto, en la búsqueda de un meta-nivel en el que debemos ser capaces de aceptar y superar la contradicción sin negarla. Al igual que Morin, otros autores comparten la idea optimista de que nos encontramos en la prehistoria del espíritu humano. Esta apuesta esperanzadora nos abre un porvenir, siempre que no seamos tan crueles de poner fin a nuestro futuro, ya sea con guerras, destrozando el planeta, o quién sabe qué otra bárbara artimaña puesta en marcha por el ser humano.

Por ello la complejidad ha de ser asumida como un desafío y no como la respuesta a una situación determinada. En ella la simplicidad y la complejidad van a unirse. La simplificación no va a ser negada, sino incorporada, igual que la necesidad de selección, jerarquización, separación, reducción, la necesidad de comunicación y la articulación entre lo disociado, que van a ser aceptadas dentro del sistema complejo. El que nos propone Morin no es un pensamiento reductor, que sólo ve elementos, ni un pensamiento globalizador, que sólo ve el todo. Transcribimos una cita de Pascal que 
Morin incorpora en su Introducción al pensamiento complejo: "Tengo por imposible conocer las partes en tanto partes sin conocer el todo, pero tengo por no menos imposible la posibilidad de conocer al todo sin conocer singularmente a las partes." (Morin, 1997, p. 144). Un círculo vicioso que estimula el desarrollo del pensamiento en un proceso enmarañado. Y este desorden sostenible no deja otro camino que el de la complejidad. Una complejidad que no apuesta por una esencia compleja del mundo, sino que la considera inconcebible. No se trata de revelar la esencia del mundo, sino de considerar a éste desde el pensamiento bajo la conciencia de su imposible aprehensión.

Ya decíamos que el ruido, la equivocación, el azar, sólo pueden ser fructíferos dentro de una potencialidad reorganizadora que los incorpore, recibiéndolos en su estructura. Para Morin el orden, el desorden y la organización son interdependientes, y no se rigen por ninguna prioridad, de modo que la complejidad es la progresión de estos tres fenómenos.

De acuerdo con Foerster, Morin afirma que la información tal cual no existe en el universo. Somos los seres humanos quienes la extraemos de la naturaleza, quienes transformamos los elementos y los acontecimientos en signos y seleccionamos como información partes destacadas del todo según nuestro interés. Un interés que no tiene porqué y aunque renuncie al todo no debe interpretarse negativamente pues puede conducirnos a un orden inesperado a través del desorden: "Mandelbrot decía que los grandes descubrimientos son el fruto de errores en la transferencia de conceptos de un campo a otro, llevados a cabo, agregaba él, por el investigador de talento. Hace falta talento para que el error se vuelva fecundo. Ello muestra también la relatividad del error y de la verdad.” (Morin, 1997, p. 161)3.

Será el talento organizador aquel capaz de vislumbrar la "serendipia" donde otros se anclen en el error4. He aquí la capacidad de reorganizar lo inesperado y servirse del azar sin requerir una estructura rígida de certeza. La verdadera racionalidad no riñe con los mitos, sino que valora la complejidad de pensamiento que entraña su creación y su uso. Esta misma deducción se recoge en el planteamiento - traído a colación por Albert Camus - que ya sostenía en la Antigua Grecia el padre de la lógica formal, Aristóteles (Camus, 1942, p. 31):

\footnotetext{
${ }^{3}$ Benoit Mandelbrot, fallecido en 2010, sería un importante matemático de origen polaco especializado en geometría fractal.

${ }^{4}$ Serendipia es un término proveniente del inglés (serendipity) y aún no aceptado por la Real Academia de la Lengua Española, que viene a referirse a un descubrimiento o hallazgo casual e inesperado que se produce cuando se busca otra cosa distinta. Habilidad de un sujeto para reconocer que ha hecho un descubrimiento importante, aunque no tenga relación con lo que buscaba. En términos más generales se podría denominar asî también a la casualidad, coincidencia o accidente.
} 
"A todas estas doctrinas les ocurre lo que ya repetimos una y otra vez, que no se destruyen a sí mismas. Y es que quien afirma que todas las cosas son verdaderas convierte en verdadero también el enunciado contrario al suyo propio, y, por tanto, convierte el suyo propio en no verdadero (ya que el enunciado contrario dice que éste no es verdadero); por su parte, el "enunciado" que afirma que todas las cosas son falsas lo afirma también de sí mismo."

En cuanto a la toma de consciencia, sólo acabamos de empezar. Morin utiliza términos como "Pre-historia del espíritu humano" o "Edad de hierro planetaria" para designar el estadio en el que se encuentra la humanidad. Un nivel del que nadie sabe si lograremos salir para dar un paso adelante, hacia la llamada de la complejidad que nos impele. Una complejidad en la que todas las áreas de conocimiento se unen, donde cada realidad ocupa su espacio, donde todos y cada uno de los mundos de verdad que somos capaces de construir vendrá a formar parte del universo de nuestra comprensión.

\section{Referencias bibliográficas}

BACHELARD, Gaston (1957). La poética del espacio. Fondo de Cultura Económica: México.

CAMUS, Albert. (1942). El mito de Sísifo. Madrid: Alianza.

DELEUZE, Gilles (1968). Diferencia y repetición. Madrid, Amorrortu editores España, 2006.

DELEUZE, Gilles (1969). Lógica del sentido. Barcelona, Ediciones Paidos Ibérica, 2005.

DELEUZE, Gilles (1973). «Pensamiento nómada». Texto extraído de La isla desierta y otros textos, (págs. 321/332), Barcelona, Pre-textos, 2005.

DELEUZE, Gilles y GUATTARI, Félix (1973). Rizoma (introducción). Valencia, Pre-textos, 2005

DELEUZE, Gilles y GUATTARI, Félix (1980). Mil mesetas: Capitalismo y esquizofrenia. Valencia, Pretextos, 2000.

DUQUE, Félix (2007). Habitar la Tierra. Medio ambiente, humanismo, ciudad. Madrid: AbadaEditores. 
GOODMAN, Nelson (1978). Maneras de hacer mundos. Visor: Madrid.

MAILLARD, Chantal. (2009) Contra el arte y otras imposturas. Pre-textos: Valencia.

MAILLARD, Chantal (1998). La razón estética. Laertes: Barcelona.

MORIN, Edgar (1997). Introducción al pensamiento complejo. Gedisa: Barcelona.

MORIN; Edgar (1999). Los siete saberes necesarios para la educación del futuro. Ediciones Paidós Ibérica: Barcelona.

TSE, Lao (2004). Tao Te Ching. RBA: Barcelona. 